\title{
Endovascular treatment of ischemic large-vessel stroke due to infective endocarditis: case series and review of the literature
}

\author{
Lucio D’Anna ${ }^{1,2}$ (D)
}

Received: 2 April 2020 / Accepted: 14 July 2020 / Published online: 22 July 2020

(C) The Author(s) 2020

\begin{abstract}
Background Mechanical thrombectomy is the standard of care, in selected patients, for acute ischemic stroke with large vessel occlusion but its use in patients with stroke secondary to infective endocarditis is controversial. We report three cases of acute ischemic stroke treated by mechanical thrombectomy and we propose an extensive review of the literature to evaluate the clinical safety and efficacy of thrombectomy in patients with stroke secondary to infective endocarditis.

Methods A comprehensive literature search was performed following a pre-specified protocol of the Preferred Reporting Items for Systematic Reviews and Meta-Analyses statement. Case reports, cases series, cross-sectional studies, case control studies, randomized controlled trials or nonrandomized controlled trials were considered that included endocarditis-related acute ischemic stroke patients who underwent mechanical thrombectomy.

Results The database search yielded 431 relevant records published until January 2020. Nineteen articles fulfilled the eligibility criteria that described thirty patients. After the thrombectomy, $13.3 \%$ of the patients experienced intracranial haemorrhage. After the procedure, the median National Institutes of Health Stroke Scale score dropped from 15 (IQR 7) to 2.5 (IQR 5.75). At 90 days, mortality was $23.3 \%$ while $46.7 \%$ of the patients were functionally independent ( $\mathrm{mRS} \leq 2$ ).

Discussion Based on our review, the use of mechanical thrombectomy in patients with large vessel occlusion due to endocarditisassociated stroke might improve patient outcome but it should be considered on a case by case base as the safety has not been well established yet. Further research on risk stratification is needed to drive clinician during the decision-making process.
\end{abstract}

Keywords Infective endocarditis $\cdot$ Stroke $\cdot$ Mechanical thrombectomy

\section{Introduction}

Acute ischemic stroke is the most common neurological complication of infective endocarditis, manifesting clinically in 20-40\% of the patients $[1,2]$. Conversely, complications may be completely silent as asymptomatic ischemia can occur in another $30-40 \%$ of patients [3]. Patients with stroke secondary to infective endocarditis have a severe prognosis leaving only less than one-third of patients alive with functional independence [4].

Treatment of patients with acute stroke secondary to infective endocarditis is suboptimal as thrombolytic therapy is

Lucio D’Anna

1.danna@imperial.ac.uk

1 Department of Stroke and Neurosciences, Charing Cross Hospital, Imperial College London NHS Healthcare Trust, Fulham Palace Road, London W6 8RF, UK

2 Division of Brain Sciences, Imperial College London, London, UK contraindicated due to high risk of haemorrhagic transformation of the infarct [5]. Mechanical thrombectomy is the standard of care, in selected patients, for acute ischemic stroke with large vessel occlusion. However, its efficacy and safety in patients with stroke secondary to infective endocarditis have limited evidence in the literature. Then, there is an urgent need of improved treatment for patients with stroke secondary to infective endocarditis.

We report here a case series of patients with stroke secondary to infective endocarditis treated with mechanical thrombectomy and a review of the current available literature on this issue.

\section{Methods}

\section{Search strategy and study selection}

We performed a systematic review following PRISMA (Fig. 1) guidance [6]. Systematic search for the reports published until January 2020 was conducted in PubMed, Cochrane, 
Fig. 1 PRISMA flowchart

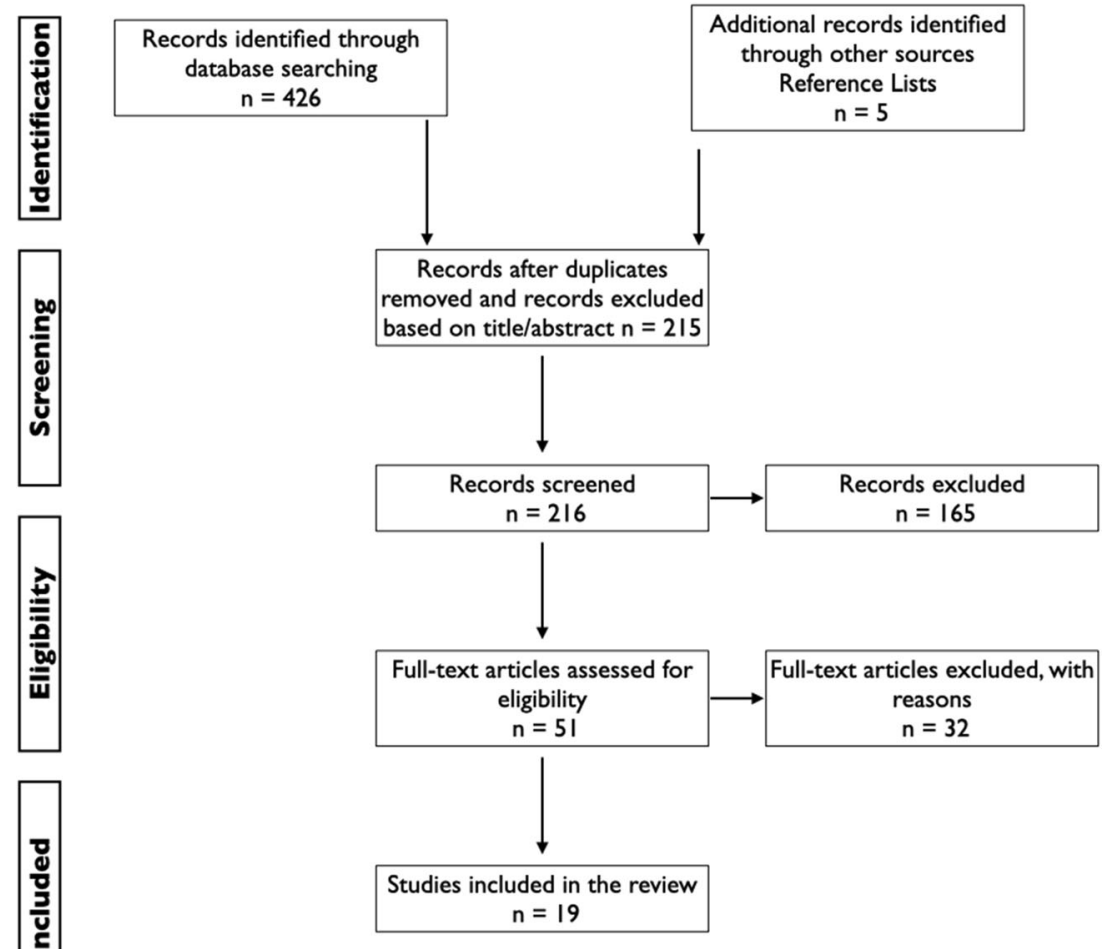

SciELO, B-on, Google scholar and clinical trial registries for relevant articles. Reference lists from all included articles and abstracts were also assessed for any additional relevant studies not identified through the initial search. For those meeting the eligibility criteria, full-text articles were obtained. Pre-defined eligibility criteria were applied. For the search strategy, we combined the terms 'stroke and endocarditis' with 'thrombectomy'. We did also the same search, but without the word 'stroke'.

\section{Eligibility criteria}

Only reports published in English were considered. We included randomized or nonrandomized controlled trials, case control studies, cross-sectional studies, case series and case reports that reported the treatment of patients ( $>18$ years old) with acute stroke secondary to infective endocarditis with mechanical thrombectomy. Title and abstracts of all retrieved articles were assessed for inclusion.

\section{Data collection process}

We extracted the following information from the reports: age, gender, site of the infective endocarditis, presence or not of atrial fibrillation, treatment with oral anticoagulant or not, blood culture pathogen, baseline National Institutes of Health Stroke Scale (NIHSS) scores, treatment with intravenous thrombolysis and site of the large vessel occlusion. We also extracted as neuroradiological outcome the presence of intracranial haemorrhage after treatment and the thrombolysis in cerebral infarction (TICI) [7] scale score defined as grade 0 , no perfusion; grade 1 , penetration with minimal perfusion; grade $2 \mathrm{~A}$, only partial filling of the entire vascular territory visualised; grade $2 \mathrm{~B}$, complete filling of all the expected vascular territories visualised but the filling is slower than normal; and grade 3 , complete perfusion. We documented the endovascular revascularization technique used, the NIHSS score after treatment and the modified Rankin Scale (mRS) at follow-up. Whenever any data is not provided, it was documented as not reported (NR).

\section{Risk of bias in individual studies}

The quality of the articles was examined according to the Quality Assessment Tool for Case Series Studies of National Heart, Lung, and Blood Institute and to the Case Reporting Guidelines of Care (2013).

\section{Data synthesis}

We summarised the data obtained in Table 1. In Table 2, we provided the $\%$ of patients with mRS score $0-1$ and $0-2$ at 90 days. We have also calculated the median (IQR) of the NIHSS at $24 \mathrm{~h}$ after the mechanical thrombectomy and the median (IQR) change in NIHSS score from baseline to $24 \mathrm{~h}$ after the procedure. 


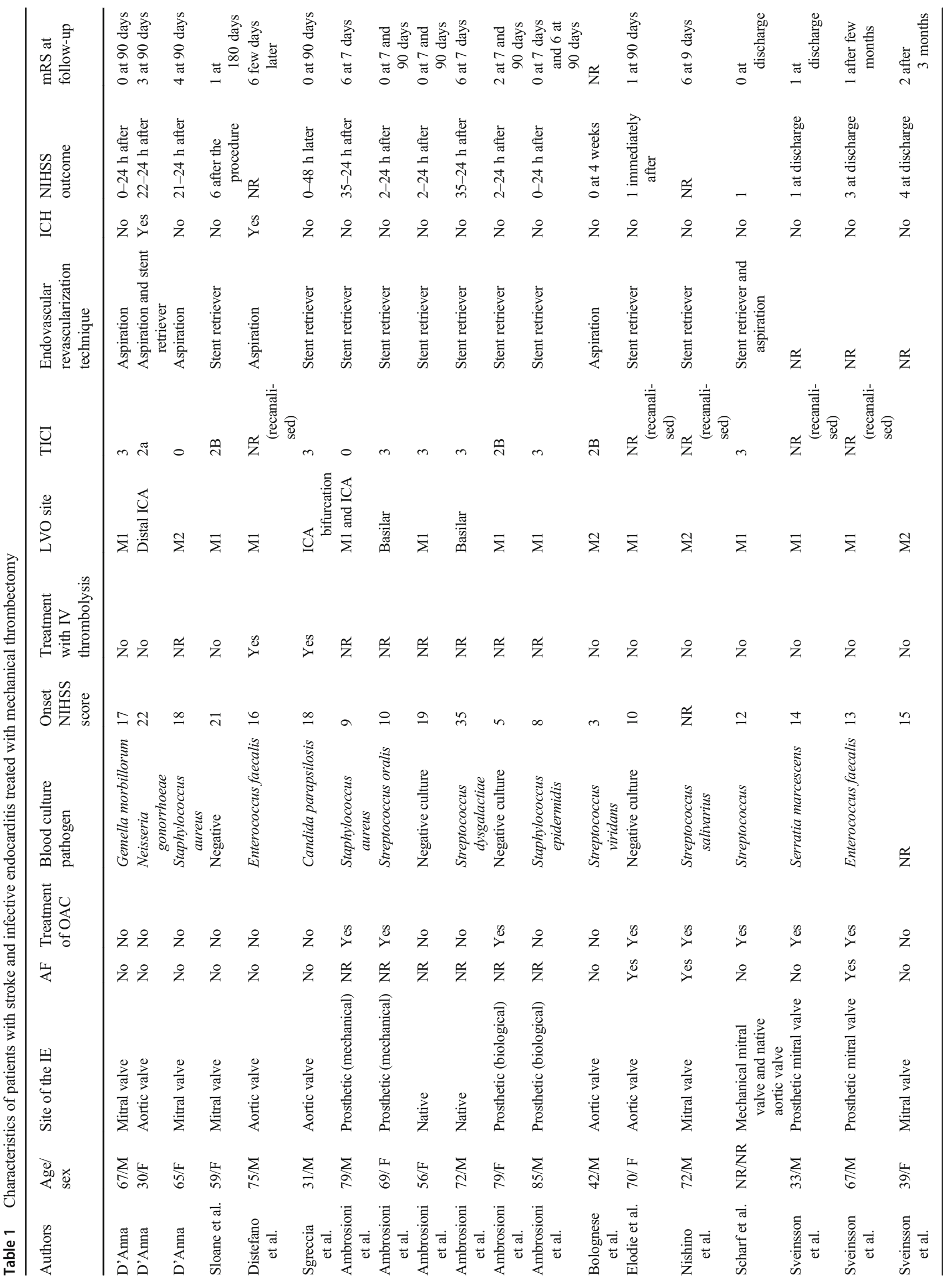




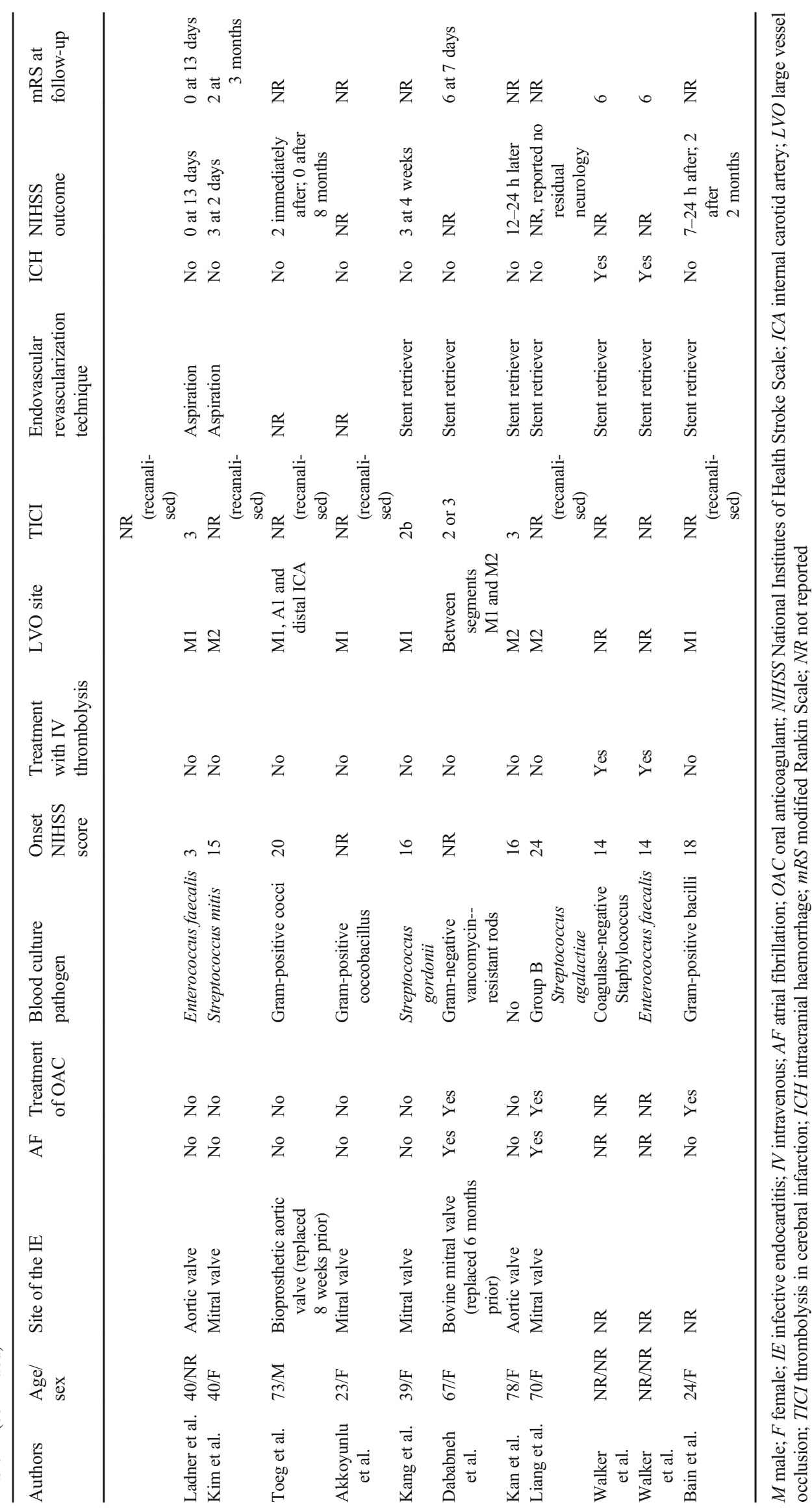


Table 2 Efficacy outcome

\begin{tabular}{ll}
\hline mRS score at 90 days & IE patients treated with MT \\
\hline mRS score $0-1$ at 90 days & $36.7 \%(11 / 30)^{*}$ \\
mRS score $0-2$ at 90 days & $46.7 \%(14 / 30)^{*}$ \\
NIHSS at $24 \mathrm{~h}$ & \\
Median score & 2.5 (IQR 5.75) \\
$\begin{array}{l}\text { Change in NIHSS score from } \\
\text { baseline to } 24 \mathrm{~h}\end{array}$ \\
Median change & -14 (IQR 10) \\
\hline
\end{tabular}

$M T$ mechanical thrombectomy; IE infective endocarditis; NIHSS National Institutes of Health Stroke Scale; $m R S$ modified Rankin Scale; $I Q R$ interquartile range

*mRS score at 90 days is not available for seven patients

\section{Case series}

\section{Case 1}

A 30-year-old female patient was brought to our emergency department $4 \mathrm{~h}$ after she developed right-sided hemiparesis, aphasia, right homonymous hemianopia, right central facial paralysis and reduced sensation in the right side of the body while she was at the gym (NIHSS 22). A month earlier, she presented to her local general practitioner (GP) with symptoms including sore throat, lethargy and general malaise. Her GP found no specific abnormalities on thorough general examination. CT of the brain showed already established changes in the left middle cerebral artery territory with an Alberta stroke program early CT score (ASPECTS) of 6. CT angiography of the brain showed a thrombus in the terminal segment of the left internal carotid artery (ICA). Thrombolysis was not performed because of the low ASPECT score on the CT brain. Mechanical thrombectomy was performed using a combination of aspiration and stent retriever, and partial recanalization was obtained (TICI 2a). A day later, the CT of the brain showed haemorrhagic transformation with an intraparenchymal haematoma centred in the left lentiform nucleus and her NIHSS was unchanged. At the same time, she developed rising fever and elevated CRP (145 mg/L). On day 4 of her admission, transthoracic echocardiogram showed vegetation on the aortic valve with associated severe aortic regurgitation. Left ventricular function was unimpaired. Blood cultures were positive for Gram-negative diplococcus, identified as Neisseria gonorrhoeae. She was therefore treated with ceftriaxone and azithromycin. After 3 months, her mRS was 3.

\section{Case 2}

A 67-year-old male patient was transferred from a local hospital to our emergency department $3 \mathrm{~h}$ after sudden onset of left sided weakness, sensory disturbance and dysarthria. His NIHSS was 17 . The patient was initially admitted for infective endocarditis of his native mitral valve and he was supposed to valve replacement surgery soon. Blood culture was positive for Gemella morbillorum. Computer tomography (CT) with CT angiography showed an occlusion of the M1 segment of the right middle cerebral artery. ASPECT score was 8 (Fig. 2a and $b$ ). Because of the evidence of endocarditis, intravenous thrombolysis was not considered an option. However, based on the large vessel occlusion, mechanical thrombectomy was performed under local anaesthetic with sedation. Endovascular thrombectomy was then performed with successful aspiration of the clot (TICI 3) (Fig. 2c and d). No immediate complications were recorded after the procedure. After $24 \mathrm{~h}$, his NIHSS dropped to 13. Mitral valve replacement surgery was successfully performed 1 month later. At neurological follow-up after 3 months, the patient showed no neurological deficits (NIHSS 0 ) and mRS score of 0 .

\section{Case 3}

A 65-year-old female patient with staphylococcal native mitral valve infective endocarditis had a witnessed onset of rightsided hemiparesis and aphasia (NIHSS 18). The patient was initially admitted in a local hospital for infective endocarditis and treated with teicoplanin and gentamicin. The patient was brought to our emergency department $3 \mathrm{~h}$ and $45 \mathrm{~min}$ after she developed her stroke symptoms. Her past medical history included also liver cirrhosis, type 2 diabetes, hypertension and breast cancer. CT angiography showed an occlusion of both M2 divisional branches. Intravenous thrombolysis was contraindicated because of the evidence of endocarditis. Mechanical thrombectomy was considered due to the large vessel occlusion. Despite several attempts at aspiration, the clot remained in situ with the final angiography demonstrating a subtotal occlusion of both the M2 divisional branches (TICI 1). After $24 \mathrm{~h}$, her NIHSS was 21 and the CT showed no haemorrhagic transformation. At neurological follow-up after 3 months, her mRS score was 4 .

\section{Results}

The database search yielded 431 relevant records published until January 2020. Nineteen articles fulfilled the eligibility criteria [8-26]. Three articles (16\%) were case series while sixteen (84\%) were single case report.

\section{Synthesis of results}

Table 1 shows the characteristics of patients with stroke and infective endocarditis treated with mechanical thrombectomy. The median age of the patients was 67 years old (IQR 32.75). 
Fig. 2 Case 2. a Axial CT head showing hyperdensity of the M1 segment of the right middle cerebral artery consistent with acute thrombus, and focal hypodensity of the right temporal lobe with loss of grey-white matter differentiation. b CT angiography demonstrating abrupt cutoff at the proximal M1 segment of the right middle cerebral artery. c Angiography confirmed occlusion of the right middle cerebral artery. d Postangiographic images

demonstrating the restoration of the flow in the right middle cerebral artery following successful thrombectomy

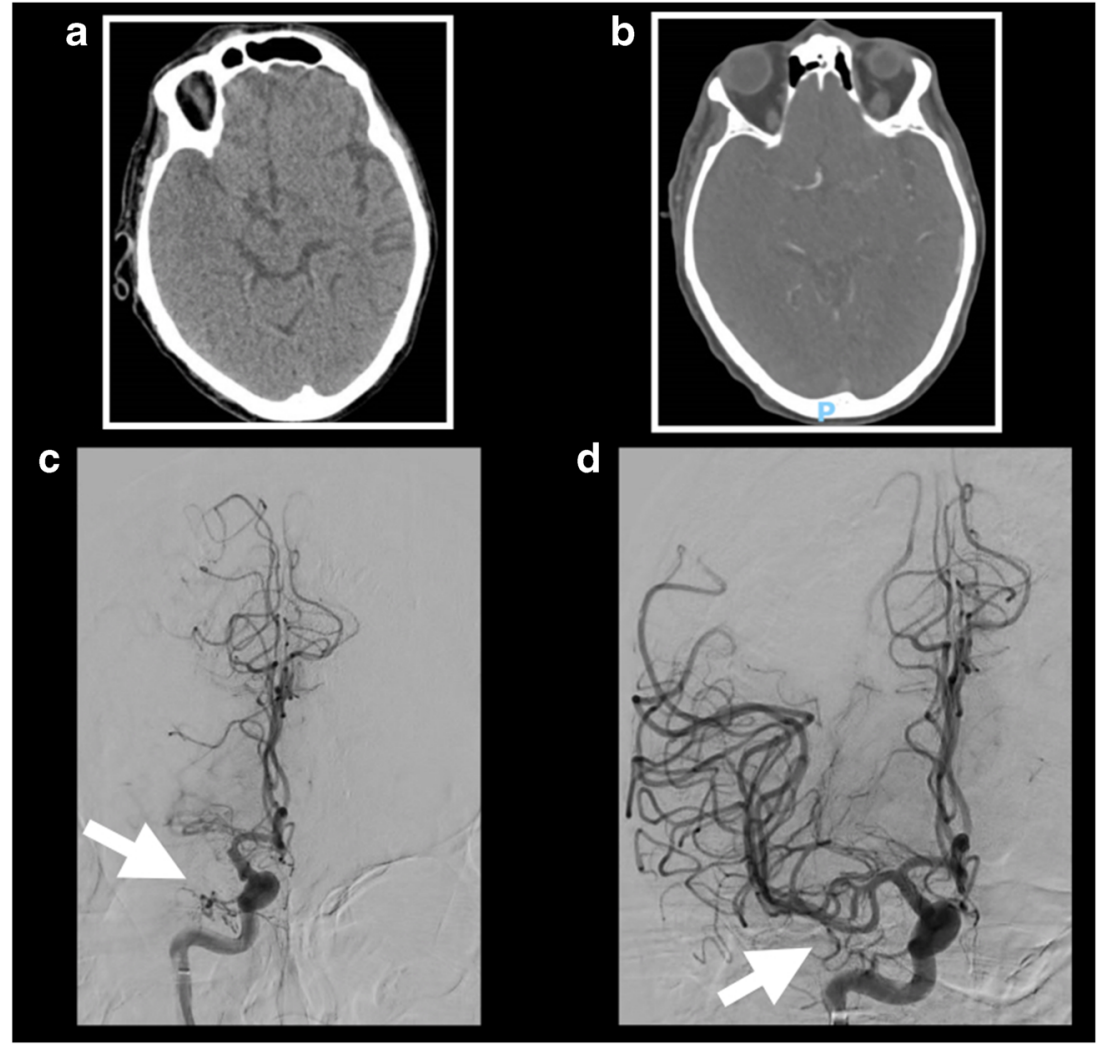

For three patients, their age was not reported. Eleven patients were men $(36.7 \%)$ while for four patients $(13.3 \%)$, the gender was not documented. The median baseline NIHSS resulted to be 15 (IQR 7). The most common site of the large vessel occlusion was the M1 (56.7\%). After the thrombectomy, nine patients $(30 \%)$ had TICI score of 3 while the TICI score of $2 \mathrm{~b}$ was obtained in four patients $(13.3 \%)$. After the treatment, four patients $(13.3 \%)$ experienced intracranial haemorrhage. After the procedure, the median NIHSS dropped to 2.5 (IQR 5.75) (Table 2).

After a follow-up of 90 days, seven patients were dead $(\mathrm{mRS}=6)(23.3 \%)$ while fourteen $(46.7 \%)$ were functionally

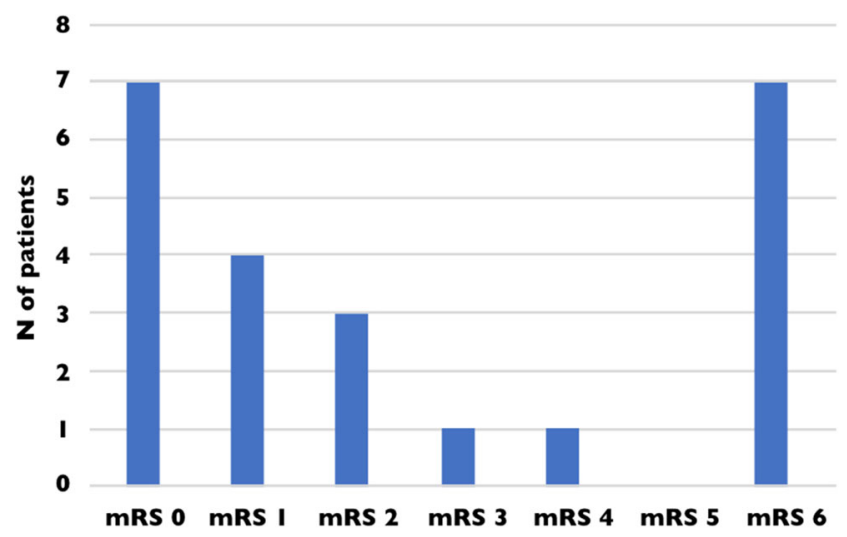

Fig. 3 Distribution of the mRS at 90 days. mRS score at 90 days is not available for seven patients independent $(\mathrm{mRS} \leq 2)$ (Table 2) (Fig. 3). Of note, mRS score at 90 days was not available for seven patients.

\section{Discussion}

Our review described the clinical presentation, management and outcome of patients treated with mechanical thrombectomy for thrombotic stroke due to infective endocarditis. Although mechanical thrombectomy is not recognised as the standard of care for acute stroke secondary to infective endocarditis, this review provides evidence of consistent benefit for endovascular treatment on disability in these patients. Indeed, in our review, $36.7 \%$ of the patients with stroke due to infective endocarditis treated with mechanical thrombectomy had a 90 -day $\mathrm{mRS} \leq 1$ while $46.7 \%$ of the patients had a mRS $\leq 2$ at 90 days. Overall, almost half of the patients with stroke due to infective endocarditis treated with mechanical thrombectomy were functionally independent after 3 months. Many previous studies showed that the occurrence of neurologic complications during infective endocarditis were associated with an increased risk of mortality [1, 2, 4, 27, 28]. More specifically, Thuny et al. [29] demonstrated that the risk of death differed according to the type of cerebrovascular disease. Patients with silent brain infarcts or transient ischemic attack had a better prognosis, whereas large stroke resulted to be a strong predictor of mortality independently of the other 
prognostic factors. Moreover, the cause of death in these patients was a direct consequence of this neurologic event. One explanation of this finding is the fact that the absence of large brain injuries carried a better prognosis and allowed early surgery to be performed with a low operative risk. This result underlines the critical need of safe reperfusion therapy for acute ischemic stroke due to infective endocarditis for salvaging ischemic brain that is not already infarcted to avoid dramatic cerebral damages.

To date, treatment with intravenous alteplase is not recommended for patients with acute ischemic stroke and symptoms consistent with infective endocarditis because of the increased risk of intracranial haemorrhage [30]. Despite the fact that the fibrinolysis might promote reperfusion through cerebral vessels occluded by septic emboli, histopathological studies suggested that cerebral infarcts caused by septic emboli are particularly prone to haemorrhagic transformation as a result of septic arteritis with erosion of the arterial wall in the recipient vessel, with or without the formation of mycotic aneurysms. The use of mechanical thrombectomy for ischemic stroke with large vessel occlusion due to septic emboli has been documented in few patients in literature so far [28]. In our review, we found that only $13.3 \%$ of the patients with endocarditisrelated acute stroke treated with thrombectomy suffered an intracranial haemorrhage after the treatment. Bettencourt et al. [28] showed that the use of intravenous alteplase alone or combined with mechanical thrombectomy was associated with a 4-fold increased risk of intracranial haemorrhage compared with mechanical thrombectomy alone. The severe bleeding complications associated with the use of intravenous alteplase may suggest that mechanical thrombectomy alone should be considered in selected patients with infective endocarditis if there is a documented large vessel occlusion.

The patterns of endocarditis-associated stroke observed in previous studies are very heterogenous. Previous studies, using conventional and DWI MRI [31] [32, 33], showed that patients with acute ischemic stroke and infective endocarditis can have a variety of ischemic lesions, including single cortical, territorial, disseminated punctate and disseminated small and large lesions in multiple vascular territories. Infarction of the middle cerebral artery territory resulted to be the most common anatomical lesion, with involvement of the middle cerebral artery tree [31]. In this review, $93.3 \%$ of the patients (28/30) treated with mechanical thrombectomy had a large vessel occlusion in the anterior circulation. Previous studies proved the value of thrombectomy in anterior circulation acute ischemic stroke within the first $6 \mathrm{~h}$ of symptom onset [34-36]. In MR CLEAN [34], 33\% of patients achieved a good clinical outcome being functionally independent with thrombectomy versus 19\% with medical therapy; in EXTEND-IA [35], the respective outcomes were $71 \%$ versus $40 \%$; in SWIFT PRIME [36], they were $60 \%$ versus $35 \%$. Recently, two recent multicentre randomized controlled trials of mechanical thrombectomy of the anterior circulation initiated at a later time windows of up to $16 \mathrm{~h}$ and $24 \mathrm{~h}$ from symptom onset have shown that endovascular therapy is safe and highly effective in carefully selected patients with advanced imaging in comparison with medical management alone $[37,38]$. The results of our review suggest that the use of thrombectomy might be an efficient and safe treatment for patients with acute large vessel occlusion of the anterior circulation associated with endocarditis and might help improve outcome; however, age, time from symptom onset, clinical severity of stroke symptoms, pre-stroke level of functioning and anatomic location of the large vessel occlusion are the most important determinants of candidacy for mechanical thrombectomy in this cohort of patients.

This study has different limitations. In first instance, our search did not find any randomized controlled trials to investigate the efficacy and safety of the mechanical thrombectomy in patients with acute stroke due to infective endocarditis as our review was based only on single case reports or case series. Secondly, there were some data missing and this made difficult to compare the results. Finally, we draw our conclusions in favour of the use of thrombectomy based on a potential publication bias.

In conclusion, based on our review, the use of mechanical thrombectomy in patients with large vessel occlusion due to endocarditis-associated stroke should be considered on a case by case base as the safety has not well established yet. Further research on risk stratification is needed to drive clinician during the decisionmaking process.

Data availability The data that support the findings of this study are available from the corresponding author, $\mathrm{LD}$, upon reasonable request.

\section{Compliance with ethical standards}

Conflict of interest The author declares that he has no conflict of interest.

\section{Ethical approval Not applicable}

Statement of informed consent Informed consent was obtained by the patients.

Open Access This article is licensed under a Creative Commons Attribution 4.0 International License, which permits use, sharing, adaptation, distribution and reproduction in any medium or format, as long as you give appropriate credit to the original author(s) and the source, provide a link to the Creative Commons licence, and indicate if changes were made. The images or other third party material in this article are included in the article's Creative Commons licence, unless indicated otherwise in a credit line to the material. If material is not included in the article's Creative Commons licence and your intended use is not permitted by statutory regulation or exceeds the permitted use, you will need to obtain permission directly from the copyright holder. To view a copy of this licence, visit http://creativecommons.org/licenses/by/4.0/. 


\section{References}

1. Sotero FD, Rosário M, Fonseca AC, Ferro JM (2019) Neurological complications of infective endocarditis. Curr Neurol Neurosci Rep 19. https://doi.org/10.1007/s11910-019-0935-x

2. Morris NA, Matiello M, Lyons JL, Samuels MA (2014) Neurologic complications in infective endocarditis: identification, management, and impact on cardiac surgery. Neurohospitalist 4:213-222. https://doi.org/10.1177/1941874414537077

3. Snygg-Martin U, Gustafsson L, Rosengren L, Alsiö Å, Ackerholm P, Andersson R, Olaison L (2008) Cerebrovascular complications in patients with left-sided infective endocarditis are common: a prospective study using magnetic resonance imaging and neurochemical brain damage markers. Clin Infect Dis 47:23-30. https:// doi.org/10.1086/588663

4. Sonneville R, Mirabel M, Hajage D, Tubach F, Vignon P, Perez P, Lavoué S, Kouatchet A, Pajot O, Mekontso Dessap A, Tonnelier JM, Bollaert PE, Frat JP, Navellou JC, Hyvernat H, Hssain AA, Tabah A, Trouillet JL, Wolff M, ENDOcardite en REAnimation Study Group (2011) Neurologic complications and outcomes of infective endocarditis in critically ill patients: the ENDOcardite en REAnimation prospective multicenter study. Crit Care Med 39: 1474-1481. https://doi.org/10.1097/CCM.0b013e3182120b41

5. Masuda J, Yutani C, Waki R, Ogata J, Kuriyama Y, Yamaguchi T (1992) Histopathological analysis of the mechanisms of intracranial hemorrhage complicating infective endocarditis. Stroke. 23:843850. https://doi.org/10.1161/01.STR.23.6.843

6. Liberati A, Altman DG, Tetzlaff J, Mulrow C, Gøtzsche PC, Ioannidis JPA, Clarke M, Devereaux PJ, Kleijnen J, Moher D (2009) The PRISMA statement for reporting systematic reviews and meta-analyses of studies that evaluate health care interventions: explanation and elaboration. J Clin Epidemiol 62:e1-e34. https:// doi.org/10.1016/j.jclinepi.2009.06.006

7. Higashida RT, Furlan AJ, Roberts $\mathrm{H}$ et al (2003) Trial design and reporting standards for intraarterial cerebral thrombolysis for acute ischemic stroke. J Vasc Interv Radiol 34:1923-1924. https://doi. org/10.1161/01.str.0000082720.85129.0a

8. Sloane KL, Raymond SB, Rabinov JD, Singhal AB (2020) Mechanical thrombectomy in stroke from infective endocarditis: case report and review. J Stroke Cerebrovasc Dis 29:104501. https://doi.org/10.1016/j.jstrokecerebrovasdis.2019.104501

9. Distefano M, Calandrelli R, Arena V, Pedicelli A, Della Marca G, Pilato F (2019) A puzzling case of cryptogenic stroke. J Stroke Cerebrovasc Dis 28:e33-e35. https://doi.org/10.1016/j. jstrokecerebrovasdis.2019.01.001

10. Kim J-M, Jeon J-S, Kim Y-W, Kang D-H, Hwang Y-H, Kim Y-S (2014) Forced arterial suction thrombectomy of septic embolic middle cerebral artery occlusion due to infective endocarditis: an illustrative case and review of the literature. Neurointervention. 9:101105. https://doi.org/10.5469/neuroint.2014.9.2.101

11. Toeg HD, Al-Atassi T, Kalidindi N, Iancu D, Zamani D, Giaccone R, Masters RG (2014) Endovascular treatment for cerebral septic embolic stroke. J Stroke Cerebrovasc Dis 23:e375-e377

12. Akkoyunlu Y, Iraz M, Kocaman G, Ceylan B, Aydin C, Aslan T (2013) Abiotrophia defectiva endocarditis presenting with hemiplegia. Jundishapur J Microbiol 6. https://doi.org/10.5812/jjm.8907

13. Kang G, Yang TK, Choi JH, Heo ST (2013) Effectiveness of mechanical embolectomy for septic embolus in the cerebral artery complicated with infective endocarditis. J Korean Med Sci 28: 1244-1247. https://doi.org/10.3346/jkms.2013.28.8.1244

14. Dababneh H, Shushrutha Hedna V, Ford J, Taimeh Z, Peters K, Mocco J, Waters MF (2012) Endovascular intervention for acute stroke due to infective endocarditis. Neurosurg Focus 32:E1. https://doi.org/10.3171/2011.11.FOCUS11263
15. Kan P, Webb S, Siddiqui AH, Levy EI (2012) First reported use of retrievable stent technology for removal of a large septic embolus in the middle cerebral artery. World Neurosurg 77:591.e1-591.e5. https://doi.org/10.1016/j.wneu.2011.05.059

16. Liang (2012) Infective endocarditis complicated by acute ischemic stroke from septic embolus: successful solitaire FR thrombectomy. Cardiol Res 3:277-280

17. Walker KA, Sampson JB, Skalabrin EJ, Majersik JJ (2012) Clinical characteristics and thrombolytic outcomes of infective endocarditisassociated stroke. Neurohospitalist. 2:87-91. https://doi.org/10. $1177 / 1941874412446199$

18. Bain MD, Hussain MS, Gonugunta V, Katzan I, Gupta R (2011) Successful recanalization of a septic embolus with a balloon mounted stent after failed mechanical thrombectomy. J Neuroimaging 21:170-172. https://doi.org/10.1111/j.1552-6569. 2009.00457.x

19. Sgreccia A, Carità G, Coskun O, Di Maria F, Benamer H, Tisserand M, Scemama A, Rodesch G, Lapergue B, Consoli A (2019) Acute ischemic stroke treated with mechanical thrombectomy and fungal endocarditis: a case report and systematic review of the literature. J Neuroradiol. https://doi.org/10.1016/j.neurad.2019.03.003

20. Ambrosioni J, Urra X, Hernández-Meneses M, Almela M, Falces C, Tellez A, Quintana E, Fuster D, Sandoval E, Vidal B, Tolosana JM, Moreno A, Chamorro A, Miró JM, Hospital Clínic Infective Endocarditis Study Group, J M M, J A, Pericàs JM, A T, M H M, A M, de la Mària CG, Garcia-Gonzalez J, Marco F, M A, Vila J, E Q, E S, Paré JC, C F, Pereda D, Cartañá R, Ninot S, Azqueta M, Sitges M, B V, Pomar JL, Castella M, J M T, Ortiz J, Fita G, Rovira I, D F, Ramírez J, Brunet M, Soy D, Castro P, Llopis J (2018) Mechanical thrombectomy for acute ischemic stroke secondary to infective endocarditis. Clin Infect Dis 66:1286-1289

21. Bolognese M, von Hessling A, Müller M (2018) Successful thrombectomy in endocarditis-related stroke: case report and review of the literature. Interv Neuroradiol 24:529-532. https://doi. org/10.1177/1591019918774761

22. Elodie O, Labeyrie PE, Aubry M, Cecile D, Roux S, Ferry T, Nighoghossian N (2019) Whipple's endocarditis diagnosed by thrombus analysis retrieved by successful mechanical thrombectomy. J Neurol Sci 400:42-43. https://doi.org/10.1016/j. jns.2019.03.009

23. Nishino W, Tajima Y, Inoue T, Hayasaka M, Katsu B, Ebihara K, Kawauchi D, Kubota M, Suda S (2017) Severe vasospasm of the middle cerebral artery after mechanical thrombectomy due to infective endocarditis: an autopsy case. J Stroke Cerebrovasc Dis 26: e186-e188. https://doi.org/10.1016/j.jstrokecerebrovasdis.2017. 06.002

24. Scharf EL, Chakraborty T, Rabinstein A, Miranpuri AS (2017) Endovascular management of cerebral septic embolism: three recent cases and review of the literature. J Neurointerv Surg 9:463465. https://doi.org/10.1136/neurintsurg-2016-012792

25. Sveinsson O, Herrman L, Holmin S (2016) Intra-arterial mechanical thrombectomy: an effective treatment for ischemic stroke caused by endocarditis. Case Rep Neurol 8:229-233

26. Ladner TR, Davis BJ, He L, Kirshner HS, Froehler MT, Mocco J (2014) Complex decision-making in stroke: preoperative mechanical thrombectomy of septic embolus for emergency cardiac valve surgery. BMJ Case Rep 2014:1-4

27. Anderson DJ, Goldstein LB, Wilkinson WE, Corey GR, Cabell CH, Sanders LL, Sexton DJ (2003) Stroke location, characterization, severity, and outcome in mitral vs aortic valve endocarditis. Neurology. 61:1341-1346. https://doi.org/10.1212/01.WNL. 0000094359.47929.E4

28. Bettencourt S, Ferro JM (2020) Acute ischemic stroke treatment in infective endocarditis: systematic review. J Stroke Cerebrovasc Dis 29:104598. https://doi.org/10.1016/j.jstrokecerebrovasdis. 2019. 104598 
29. Thuny F, Avierinos JF, Tribouilloy C, Giorgi R, Casalta JP, Milandre L, Brahim A, Nadji G, Riberi A, Collart F, Renard S, Raoult D, Habib G (2007) Impact of cerebrovascular complications on mortality and neurologic outcome during infective endocarditis: a prospective multicentre study. Eur Heart J 28:1155-1161. https:// doi.org/10.1093/eurheartj/ehm005

30. Demaerschalk BM, Kleindorfer DO, Adeoye OM, Demchuk AM, Fugate JE, Grotta JC, Khalessi AA, Levy EI, Palesch YY, Prabhakaran S, Saposnik G, Saver JL, Smith EE, American Heart Association Stroke Council and Council on Epidemiology and Prevention (2016) Scientific rationale for the inclusion and exclusion criteria for intravenous alteplase in acute ischemic stroke. Stroke. 47:581-641. https://doi.org/10.1161/str. 0000000000000086

31. Singhal AB, Topcuoglu MA, Buonanno FS (2002) Acute ischemic stroke patterns in infective and nonbacterial thrombotic endocarditis: a diffusion-weighted magnetic resonance imaging study. Stroke. 33:1267-1273. https://doi.org/10.1161/01.STR. 0000015029.91577 .36

32. Kim SJ, Lee JY, Kim TH, Kim SC, Choi YH, Pai H, Choi WS (1998) Imaging of the neurological complications of infective endocarditis. Neuroradiology. 40:109-113. https://doi.org/10.1007/ s002340050549

33. Bakshi R, Wright PD, Kinkel PR, Bates VE, Mechtler LL, Kamran S, Pullicino PM, Sirotkin I, Kinkel WR (1999) Cranial magnetic resonance imaging findings in bacterial endocarditis: the neuroimaging spectrum of septic brain embolization demonstrated in twelve patients. J Neuroimaging 9:78-84. https://doi.org/10.1111/ jon19999278

34. Berkhemer OA, Fransen PSS, Beumer D, van den Berg L, Lingsma HF, Yoo AJ, Schonewille WJ, Vos JA, Nederkoorn PJ, Wermer MJ, van Walderveen M, Staals J, Hofmeijer J, van Oostayen J, Lycklama à Nijeholt GJ, Boiten J, Brouwer PA, Emmer BJ, de Bruijn SF, van Dijk L, Kappelle LJ, Lo RH, van Dijk E, de Vries J, de Kort PL, van Rooij W, van den Berg J, van Hasselt B, Aerden LA, Dallinga RJ, Visser MC, Bot JC, Vroomen PC, Eshghi O, Schreuder TH, Heijboer RJ, Keizer K, Tielbeek AV, den Hertog H, Gerrits DG, van den Berg-Vos R, Karas GB, Steyerberg EW, Flach HZ, Marquering HA, Sprengers ME, Jenniskens SF, Beenen LF, van den Berg R, Koudstaal PJ, van Zwam W, Roos YB, van der Lugt A, van Oostenbrugge R, Majoie CB, Dippel DW, MR
CLEAN Investigators (2015) A randomized trial of intraarterial treatment for acute ischemic stroke. N Engl J Med 372:11-20. https://doi.org/10.1056/NEJMoa1411587

35. Campbell BCV, Mitchell PJ, Kleinig TJ, Dewey HM, Churilov L, Yassi N, Yan B, Dowling RJ, Parsons MW, Oxley TJ, Wu TY, Brooks M, Simpson MA, Miteff F, Levi CR, Krause M, Harrington TJ, Faulder KC, Steinfort BS, Priglinger M, Ang T, Scroop R, Barber PA, McGuinness B, Wijeratne T, Phan TG, Chong W, Chandra RV, Bladin CF, Badve M, Rice H, de Villiers L, Ma H, Desmond PM, Donnan GA, Davis SM, EXTEND-IA Investigators (2015) Endovascular therapy for ischemic stroke with perfusionimaging selection. N Engl J Med 372:1009-1018. https://doi.org/ 10.1056/NEJMoa1414792

36. Saver JL, Goyal M, Bonafe A et al (2015) Stent-retriever thrombectomy after intravenous t-PA vs. t-PA alone in stroke. N Engl J Med. https://doi.org/10.1056/NEJMoa1415061

37. Albers GW, Marks MP, Kemp S, Christensen S, Tsai JP, OrtegaGutierrez S, McTaggart RA, Torbey MT, Kim-Tenser M, LeslieMazwi T, Sarraj A, Kasner SE, Ansari SA, Yeatts SD, Hamilton S, Mlynash M, Heit JJ, Zaharchuk G, Kim S, Carrozzella J, Palesch YY, Demchuk AM, Bammer R, Lavori PW, Broderick JP, Lansberg MG (2018) Thrombectomy for stroke at 6 to 16 hours with selection by perfusion imaging. N Engl J Med 378:708-718. https://doi.org/10.1056/NEJMoa1713973

38. Nogueira RG, Jadhav AP, Haussen DC, Bonafe A, Budzik RF, Bhuva P, Yavagal DR, Ribo M, Cognard C, Hanel RA, Sila CA, Hassan AE, Millan M, Levy EI, Mitchell P, Chen M, English JD, Shah QA, Silver FL, Pereira VM, Mehta BP, Baxter BW, Abraham MG, Cardona P, Veznedaroglu E, Hellinger FR, Feng L, Kirmani JF, Lopes DK, Jankowitz BT, Frankel MR, Costalat V, Vora NA, Yoo AJ, Malik AM, Furlan AJ, Rubiera M, Aghaebrahim A, Olivot JM, Tekle WG, Shields R, Graves T, Lewis RJ, Smith WS, Liebeskind DS, Saver JL, Jovin TG, DAWN Trial Investigators (2018) Thrombectomy 6 to 24 hours after stroke with a mismatch between deficit and infarct. N Engl J Med 378:11-21. https://doi. org/10.1056/NEJMoa1706442

Publisher's note Springer Nature remains neutral with regard to jurisdictional claims in published maps and institutional affiliations. 